\title{
Lack of efficacy of low-dose spironolactone as adjunct treatment to conventional congestive heart failure treatment in dogs
}

\author{
S. SCHULLER $* \dagger$ \\ N. VAN ISRAËL*,+ \\ S. VANBELLE ${ }^{\S}$ \\ C. CLERCX* \& \\ K. MCENTEE*
}

*Department of Small Animal Clinical Studies, Faculty of Veterinary Medicine, University of Liège, Boulevard de Colonster, Liège, Belgium; ${ }^{\dagger}$ University College Dublin, University Veterinary Hospital, Belfield, Dublin, Ireland; ${ }^{\star} A C A P U L C O$ Animal Cardiopulmonary Consultancy, Masta, Belgium; ${ }^{\S}$ Department of Biostatistics, University of Liège, Centre Hospitalier Universitaire, Sart Tilman, Liège, Belgium

\begin{abstract}
Schuller, S., Van Israël, N., Vanbelle, S., Clercx, C., McEntee, K. Lack of efficacy of low-dose spironolactone as adjunct treatment to conventional congestive heart failure treatment in dogs. J. vet. Pharmacol. Therap. 34, 322-331.
\end{abstract}

Aldosterone plays an important role in the pathophysiology of heart failure. Aldosterone receptor blockade has been shown to reduce morbidity and mortality in human patients with advanced congestive left ventricular heart failure. This study was designed to assess the efficacy and tolerance of long-term low-dose spironolactone when added to conventional heart failure treatment in dogs with advanced heart failure. Eighteen client-owned dogs with advanced congestive heart failure due to either degenerative valve disease $(n=11)$ or dilated cardiomyopathy $(n=7)$ were included in this prospective, placebocontrolled, double-blinded, randomized clinical study. After initial stabilization including furosemide, angiotensin-converting enzyme inhibitors, pimobendan and digoxin, spironolactone at a median dose of $0.52 \mathrm{mg} / \mathrm{kg}$ (range $0.49-0.8 \mathrm{mg} / \mathrm{kg})$ once daily $(n=9)$ or placebo $(n=9)$ was added to the treatment, and the dogs were reassessed 3 and 6 months later. Clinical scoring, echocardiography, electrocardiogram, systolic blood pressure measurement, thoracic radiography, sodium, potassium, urea, creatinine, alanine aminotransferase, aldosterone and aminoterminal atrial natriuretic propeptide were assessed at baseline, 3 and 6 months. Survival times were not significantly different between the two treatment groups. Spironolactone was well tolerated when combined with conventional heart failure treatment.

(Paper received 21 March 2010; accepted for publication 1 August 2010)

Simone Schuller, University College Dublin, University Veterinary Hospital, Belfield, Dublin 4, Ireland. E-mail: simone.schuller@ucd.ie

\section{INTRODUCTION}

In humans and animals with advanced congestive heart failure, serum aldosterone concentrations are increased as a result of the activation of the renin-angiotensin-aldosterone system (RAAS) (Swedberg et al., 1990). Aldosterone plays a key role in the pathophysiology of congestive heart failure. It promotes the retention of sodium, the loss of magnesium and potassium, sympathetic activation, parasympathetic inhibition, myocardial and vascular remodelling, baroceptor dysfunction and impairs arterial compliance (Struthers, 2004). The actions of aldosterone, although beneficial in the short term, contribute to the progression of heart failure in the long term (Katz, 2003). Treatment with angiotensin conversion enzyme (ACE) inhibitors reduces angiotensin II and aldosterone production and has been shown to be of great clinical benefit in the treatment of heart failure in humans (CONSENSUS study, 1987) and dogs (COVE study, 1995; IMPROVE study, 1995; Ettinger et al., 1998;
BENCH study, 1999). However, in up to $45 \%$ of human patients with heart failure, serum aldosterone and/or angiotensin II concentrations are elevated despite treatment with ACE inhibitors, a phenomenon called 'aldosterone escape' (MacFadyen et al., 1999; Van de Wal et al., 2006). Treatment with ACE inhibitors may therefore not be sufficient to control aldosterone production, and concurrent aldosterone receptor blockade may be beneficial. The 'Randomised Aldactone Evaluation Study' (RALES), a large, multicentre study involving 1663 human patients, showed that spironolactone, when added in a low dose (25 mg/day), which will not lead to significant diuresis, to conventional treatment with ACE inhibitors, diuretics and cardiac glycosides, significantly reduces morbidity and mortality in human patients with advanced left ventricular dysfunction (Pitt et al., 1999). The beneficial effect of spironolactone on survival was most pronounced in patients with elevated serum concentrations of procollagen III aminoterminal peptide (PIIINP), a serum marker of increased extracellular matrix 
turnover. It was suggested that spironolactone acts by blunting aldosterone-induced myocardial remodelling, in particular myocardial fibrosis (Zannad et al., 2000). Further subgroup studies showed a significant decrease in plasma brain natriuretic peptide (BNP) and N-terminal peptide of the aminoterminal atrial natriuretic propeptide (NT-proANP) as well as a significant increase in plasma angiotensin II and aldosterone in patients treated with low-dose spironolactone, indicating that, at this dose, spironolactone induced significant neurohormonal changes that could be responsible for the beneficial effect on morbidity and mortality (Rousseau et al., 2002).

However, combined treatment with ACE inhibitors and spironolactone has been a concern in humans, especially for patients with reduced renal function, given that both drugs work synergistically via reduction in aldosterone secretion (ACE inhibitors) and inhibition of aldosterone binding to its receptor (spironolactone) and thus can lead to life-threatening hyperkalaemia (Berry \& McMurray, 2001; Juurlink et al., 2004).

A recent clinical trial showed a significant decrease in mortality in dogs with moderate to severe mitral valve disease when spironolactone was added at $2 \mathrm{mg} / \mathrm{kg}$ once daily (Bernay et al., 2010). Concurrent treatment with an ACE inhibitor and spironolactone was well tolerated in that study.

The aims of the present randomized, prospective, doubleblinded, placebo-controlled clinical study were firstly to assess the efficacy of long-term treatment with a low dose of spironolactone in addition to conventional treatment including furosemide, ACE inhibitors, pimobendan and digoxin on survival and on clinical, biochemical and neuroendocrine parameters in dogs with advanced heart failure due to either degenerative valve disease (DVD) or dilated cardiomyopathy (DCM) and secondly to evaluate its tolerance in this category of patients. The dose of spironolactone used in this trial $(0.5-0.8 \mathrm{mg} / \mathrm{kg}$ once daily) was chosen to be clearly below the approved diuretic dose in dogs (2-4 mg/kg once daily) to show that potential positive effects of spironolactone are due to other than diuretic effects.

\section{MATERIAL AND METHODS}

The study was designed as a prospective, randomized, doubleblined placebo-controlled clinical trial. It was performed at the Department of Small Animal Clinical Studies of the Faculty of Veterinary Medicine, University of Liège (Belgium). The study protocol was approved by the ethics committee for animal research of the University of Liège (Belgium). Informed consent was obtained from each owner before enrolment of the animal in the study protocol.

\section{Animals}

Eighteen client-owned dogs of various breeds were included. Inclusion criteria were presence of advanced heart failure [Classes II and III according to the Scandinavian modified New York Heart Association system (NYHA); Table 1] secondary to either DVD or DCM, absence of severe concurrent disease and
Table 1. Scandinavian modified New York Heart Association (NYHA) system for classification heart failure stage in dogs with mitral valve disease

\begin{tabular}{lc}
\hline NYHA class & Clinical findings \\
\hline I & Asymptomatic dogs with murmurs but no \\
II & Asymptomatic dogs with murmurs and \\
& cardiac enlargement but no pulmonary \\
& oedema or congestion. \\
III & Slightly or moderately symptomatic dogs \\
& (dyspnoea, increased heart rate and \\
& disappearance of sinus arrhythmia) with \\
& murmurs, cardiac enlargement and \\
& interstitial pulmonary oedema. \\
& Severely symptomatic dogs with murmurs, \\
IV & cardiac enlargement and alveolar \\
& pulmonary oedema.
\end{tabular}

clinically stable heart disease for a minimum of 4 weeks on conventional treatment. Accepted conventional treatments were furosemide, ACE inhibitors (benazepril or enalapril), pimobendan and digoxin. Exclusion criteria were uncontrolled congestive heart failure despite conventional treatment, severe concurrent extra-cardiac disease and need for spironolactone at diuretic dose (2-4 mg/kg/day). Initial diagnosis and staging were based on history, clinical findings, electrocardiogram (ECG), thoracic radiography and echocardiography. Haematology and serum biochemistry (not shown) were performed in all patients as part of the initial work up.

\section{Treatment groups}

The dogs were paired in order of admission to the study and assigned in either of two treatment groups: Group 1 received spironolactone at a median dose of $0.52 \mathrm{mg} / \mathrm{kg}$ once daily (range $0.5-0.8 \mathrm{mg} / \mathrm{kg}$ ); Group 2 received a placebo (vehicle tablets) in addition to conventional treatment. Spironolactone ( $2 \mathrm{mg}$ ) and placebo tablets were both prepared by the Department of Pharmacology of the Centre Hospitalier Universitaire of the University of Liège and were identical in appearance. The tablets were administered per mouth with food. The study was double-blinded, with the investigators and the owners unaware of treatment group assignment of individual dogs.

\section{Clinical evaluation}

The dogs included in the study were scheduled for evaluation 4 weeks after the start of the initial stabilization period (baseline) and after 1 week, and 3 and 6 months of treatment with either spironolactone or placebo. At baseline, 3 and 6 months dogs were evaluated by history, physical examination, indirect systolic blood pressure measured by Doppler method, standard six-lead ECG for $5 \mathrm{~min}$, right lateral and dorsoventral thoracic radiography and echocardiography. Plasma sodium, potassium, urea, creatinine and alanine aminotransferase (ALT) were measured. At the 1-week visit, a history and physical examination were 
performed and a blood sample was taken for measurement of sodium, potassium, urea and creatinine. The clinical variables were assessed using a scoring system widely used in veterinary clinical cardiac trials (IMPROVE study, 1995; Smith et al., 2005; Table 2). Additional historical parameters were the following: presence or absence of syncope, vomiting, diarrhoea, polydipsia and polyuria. Parameters assessed during physical examination were body weight, colour of mucous membranes, capillary refill time, presence of a jugular pulse or jugular distension, dyspnoea, pulse rate and quality, the presence of a precordial thrill, rectal temperature, heart rate, respiratory rate, murmur grade, intensity, radiation and point of maximum intensity and respiratory noises.

Indirect systolic blood pressure measurement was performed using an ultrasonic Doppler flow detector (Parks Medical Electronics, Aloha, OR, USA) with all dogs in lateral recumbence. Either the metacarpal or metatarsal artery was used while the paw was held at the level of the right atrium. Cuff size and location used were recorded, and the same technique was maintained for each individual dog for all consecutive visits. A total of four measurements were performed. The first measurement was discarded, and the mean systolic blood pressure was calculated as a mean of the following three measurements.

A standard 6-lead ECG (Spacelabs Burdick, Deerfield, WI, USA) was performed with patients positioned in right lateral recumbency. The ECG trace was assessed for heart rate, waveforms, intervals and the presence or absence of arrhythmias. Thoracic radiographs were assessed for size of the cardiac silhouette, chamber enlargements and signs of pulmonary congestion. The size of the heart was measured using the vertebral heart size (VHS), which is a number that normalizes heart size to body size using mid-thoracic vertebrae as units of measure (Buchanan \& Bücheler, 1995). Others have called this vertebral heart system.

\section{Haemodynamic evaluation}

Two-dimensional, M-mode and Doppler echocardiography were performed without sedation using a 7.5, 5.0 and $2.5 \mathrm{MHz}$ transducer (Esaote Megas, Pie Medical Equipment, Maastricht, the Netherlands). Three measurements were made for each variable, and the average value was used in the statistical analysis. Simultaneous ECG was performed during the echocardiographic examination. Two-dimensional and M-mode variables were determined in accordance with the guidelines established by the American Society of Echocardiography (Schiller et al., 1989; O'Grady et al., 2005). All echocardiographic parameters measured are listed in Table 5.

\section{NT-proANP and aldosterone}

At baseline, 3- and 6- month blood samples were collected in iced 5- mL polyethylene tubes containing EDTA $(25 \mu \mathrm{mol})$ and aprotinin (Aprotinin, Trasylol ${ }^{\circledR}$; Bayer, Leverkusen, Germany) for measurement of NT-proANP and in dry tubes for measurement

Table 2. Scoring system used for clinical variables evaluated in dogs with heart failure (Amended from The Improve Study Group, 1995)

\begin{tabular}{|c|c|c|}
\hline Cough scores & Respiratory effort & Appetite \\
\hline $0-$ None & $0-$ Normal & 1 - Increased \\
\hline 1 - Occasional & 1 - Mildly increased effort & 2 - Normal \\
\hline 2 - Frequent & 2 - Laboured & 3 - Decreased \\
\hline 3 - Persistent & 3 - Respiratory distress & 4 - Markedly decreased \\
\hline Mobility & Attitude & Activity \\
\hline $\begin{array}{l}1 \text { - Very good: walks well, runs, capable of } \\
\text { some strenuous activity. }\end{array}$ & $\begin{array}{l}1 \text { - Increased: has stronger desire and } \\
\text { interest than in the past to go out for } \\
\text { walks or play with owner. Appears more } \\
\text { alert and responsive to surrounding } \\
\text { environment. }\end{array}$ & $\begin{array}{l}1 \text { - High: moves around with ease, capable } \\
\text { of climbing stairs or running short } \\
\text { distances. Alert and responsive to } \\
\text { external stimuli. }\end{array}$ \\
\hline $\begin{array}{l}2 \text { - Good: walks well, will run a short } \\
\text { distance or pulls on lead but unable to do } \\
\text { strenuous activity, tires easily after } \\
\text { walking } 1-2 \text { blocks. }\end{array}$ & $\begin{array}{l}2 \text { - Remained the same: has } \\
\text { approximately the same degree of interest } \\
\text { and desire to go out for walks or play } \\
\text { with the owner as in the past, is more alert to } \\
\text { the surrounding environment as before. }\end{array}$ & $\begin{array}{l}2 \text { - Moderate: tends to be inactive but } \\
\text { moves around a few times per day. Has } \\
\text { difficulty with stairs and avoids long } \\
\text { walks. }\end{array}$ \\
\hline $\begin{array}{l}3 \text { - Moderate: will walk, but for a limited } \\
\text { distance before needing to rest. }\end{array}$ & $\begin{array}{l}3 \text { - Decreased: has some interest, but plays } \\
\text { less often, and has decreased interest to } \\
\text { go for a run or walk. }\end{array}$ & $\begin{array}{l}3 \text { - Low: generally inactive, tendency to } \\
\text { remain in one place most of the day and } \\
\text { is unable to climb stairs or walk more } \\
\text { than short distance. }\end{array}$ \\
\hline $\begin{array}{l}4 \text { - Poor: can only walk a few yards before } \\
\text { needing to rest. }\end{array}$ & & $\begin{array}{l}4 \text { - Minimal: remains inactive all day and } \\
\text { only gets up to eat, drink or urinate. }\end{array}$ \\
\hline $\begin{array}{l}5 \text { - Very poor: to get up and move is a } \\
\text { major effort, only able to move a few } \\
\text { steps before resting. }\end{array}$ & & $\begin{array}{l}5 \text { - Incapacitated: will only get up or move } \\
\text { if strongly encouraged by owner. }\end{array}$ \\
\hline
\end{tabular}


of aldosterone. After centrifugation within $30 \mathrm{~min}(2000 \times \boldsymbol{g}$, $10 \mathrm{~min}, 4^{\circ} \mathrm{C}$ ), serum and plasma samples were frozen at $-20^{\circ} \mathrm{C}$ and run batch wise at the end of the trial using radioimmunoassays validated for use in canine plasma (Aldosterone RIA: Coat-a-count TKAL 1,2; Diagnostic Products Corporation, Los Angeles, CA, USA). ${ }^{1}$ All measurements were performed in duplicate. For aldosterone, the antiserum used had a crossreactivity of $100 \%$ for aldosterone and of $<0.03 \%$ for other compounds. The lowest limit of detection was $30.5 \mathrm{pmol} / \mathrm{l}$ and the coefficient of variation was $7.7 \%$. For NT-proANP, the antiserum used had a cross-reactivity of $100 \%$ for human NT pro-ANP1-126 and NT-proANP 1-98 and a cross-reactivity of $<0.01 \%$ for other natriuretic peptides. The lowest limit of detection was $0.03 \mathrm{fmol} / \mathrm{l}$ and the coefficient of variation in the study was $5.5 \%$.

\section{Endpoints}

Predefined endpoints were end of the trial, euthanasia, death or discontinuation of the trial as a direct consequence of heart failure and discontinuation of the trial for reasons other than worsening of heart failure.

\section{Statistical analysis}

The survival curves of the two groups were determined by the Kaplan-Meier method and were compared by the log-rank test and the Cox proportional hazard model.

The results were expressed as mean \pm standard deviation (SD) for quantitative variables. Baseline characteristics of the two treatment groups were compared to assess the level of balance between the two groups: the Wilcoxon rank-sum test was used to compare quantitative variables, while the chi-squared test was used for qualitative variables. To study the evolution of the echocardiographical and biochemical parameters over time, generalized linear mixed models were used, including the baseline overall clinical score as covariate to account for baseline difference between the two groups. Calculations were always carried out on the maximum number of data available. Missing data were not replaced. Results were considered to be significant at the $5 \%$ critical level $(P<0.05)$. Statistical analysis was carried out using SAS (version 9.1 for Windows, SAS Institute Inc., Cary, NC, USA) and S-Plus (version 9.0, TIBCO Software Inc., Palo Alto, CA, USA) software packages.

Power calculation was performed after the end of the trial and was based on the mean survival times observed in the study (Lachin \& Foulkes, 1986). Power calculation was not performed pretrial because specific survival data needed to formulate a reasonable assumption were not available and extrapolations

\footnotetext{
${ }^{1}$ NT-proANP •Biotop (Medipolis center, Kivihartjuntie 11, Fin-90220 OULU - Finland), code BT02-100 tubes. The antibody employed in this kit is directed to the amino acid residues 80-96 of the human ANP sequence, which is identical to that observed in canine and feline NT-proANP over that region.
}

from the human RALES trial (Pitt et al., 1999) were considered inappropriate.

\section{RESULTS}

Animals

A total of 18 dogs were enrolled in the study between February 2003 and October 2004. Breeds represented were Bichon Frise $(n=3)$, Labrador retriever $(n=2)$, mixed breeds $(n=3)$ and 1 each of the following: Miniature Poodle, Maltese terrier, Wirehaired Dachshund, Miniature Pinscher, Rough Collie, German Shepherd, Boxer, Newfoundland, Whippet and Rottweiler.

\section{Baseline characteristics}

Baseline characteristics of the dogs enrolled in the study are presented in Table 3. At baseline, the overall clinical score was significantly higher in the spironolactone group than in the control group $(7.1 \pm 1.8$ vs. $5.2 \pm 1.6, P<0.05)$, because of higher mobility and activity scores. Atrial fibrillation was present in three dogs from the spironolactone group but only $1 \mathrm{dog}$ in the control group. Mean serum potassium, while being within the normal range in all dogs, was significantly higher in the spironolactone group at baseline $(4.4 \pm 0.6$ vs. $3.8 \pm 0.3 \mathrm{mmol} / \mathrm{l}$, $P<0.05)$.

\section{Progression of clinical and haemodynamic parameters, NT-proANP} and aldosterone

No adverse events were observed in the study population over the study period of 6 months. Progression of clinical, haemodynamic, biochemical and neurohumoral parameters in the two treatment groups during the study is presented in Tables 4 and 5. No significant difference was found between the two treatment groups with regard to the clinical score. The overall clinical score significantly increased in dogs with DCM but not in dogs with DVD over time $(P<0.01)$. Mean heart failure class increased over time in both treatment groups $(P<0.01)$. Dogs in the control group had a higher risk of moving into a higher class of heart failure than dogs in the spironolactone group $(P<0.05)$. Mean NT-proANP concentration increased significantly over time in the spironolactone group and significantly decreased in the control group $(P<0.0001)$. Plasma aldosterone concentrations ranged between 0 and $461 \mathrm{pmol} / \mathrm{l}$ (mean $135 \pm 106 \mathrm{pmol} / \mathrm{l})$. There was no significant difference between groups and no significant changes over time; however, only a small number of samples was available for assessment at 6 months.

\section{Outcome - endpoints}

There was no significant difference between the two treatment groups regarding survival (Fig. 1). The survival probability decreased with increasing doses of furosemide $(P<0.05)$. There was no effect of pimobendan on the survival probability $(P>0.05)$. 
Table 3. Baseline characteristics of the 18 dogs included in the study. Results are reported for the entire population $(n=18)$ and according to the treatment group (spironolactone/placebo)

\begin{tabular}{|c|c|c|c|c|}
\hline Characteristics & Total $n=18$ & Spironolactone $n=9$ & Placebo $n=9$ & $P$ \\
\hline \multicolumn{5}{|l|}{ Sex } \\
\hline Female (entire/neutered) & 7 & $2(1 / 1)$ & $5(2 / 3)$ & 0.15 \\
\hline Body weight (kg) & $23.2 \pm 18.4$ & $29.7 \pm 20.9$ & $16.7 \pm 13.7$ & 0.17 \\
\hline \multicolumn{5}{|l|}{ Pathology } \\
\hline \multicolumn{5}{|l|}{ Clinical score } \\
\hline Cough & $0.6 \pm 0.6$ & $0.7 \pm 0.7$ & $0.4 \pm 0.5$ & 0.52 \\
\hline Dyspnoea & $0.3 \pm 0.5$ & $0.2 \pm 0.4$ & $0.4 \pm 0.5$ & 0.35 \\
\hline Appetite & $2.1 \pm 0.5$ & $2.1 \pm 0.8$ & $2.0 \pm 0.0$ & 0.99 \\
\hline Attitude & $1.9 \pm 0.6$ & $2.0 \pm 0.7$ & $1.8 \pm 0.4$ & 0.46 \\
\hline Mobility* & $1.8 \pm 0.7$ & $2.2 \pm 0.7$ & $1.4 \pm 0.5$ & 0.021 \\
\hline $\mathrm{PU} / \mathrm{PD}$ & 13 & 6 & 7 & 0.60 \\
\hline \multicolumn{5}{|l|}{ Clinical parameters } \\
\hline Increased respiratory effort & $0.22 \pm 0.44$ & $0.33 \pm 0.50$ & $0.28 \pm 0.46$ & 0.62 \\
\hline Respiratory rate (breaths/min) & $30.4 \pm 24.8$ & $24.6 \pm 20.4$ & $36.3 \pm 28.5$ & 0.37 \\
\hline Heart rate (beats/min) & $133.2 \pm 27.5$ & $139.8 \pm 30.7$ & $126.7 \pm 23.8$ & 0.23 \\
\hline \multicolumn{5}{|l|}{ Heart failure stage } \\
\hline II & 12 & 5 & 7 & \multirow[t]{3}{*}{0.23} \\
\hline III & 6 & 4 & 2 & \\
\hline IV & & - & - & \\
\hline Systolic blood pressure (mmHg) & $138 \pm 33$ & $152 \pm 36$ & $121 \pm 20$ & 0.10 \\
\hline VHS & $11.8 \pm 1.2$ & $11.3 \pm 0.8$ & $12.3 \pm 1.3$ & 0.11 \\
\hline \multicolumn{5}{|l|}{ Serum biochemistry } \\
\hline Aldosterone (pmol/l) & $139 \pm 116$ & $147 \pm 144$ & $129 \pm 76$ & 0.63 \\
\hline \multicolumn{5}{|l|}{ Number of dogs receiving medication } \\
\hline Furosemide ${ }^{\dagger}(n)$ & 17 & 8 & 9 & 0.30 \\
\hline Mean Furosemide dose (mg.kg/day) & $4.2 \pm 2.1$ & $4.0 \pm 1.7$ & $4.4 \pm 2.4$ & 0.85 \\
\hline \multicolumn{5}{|l|}{ ACE inhibitor } \\
\hline Benazepril $^{\ddagger}(n)$ & 15 & 8 & 7 & 0.53 \\
\hline Enalapril $^{\ddagger}(n)$ & 3 & 1 & 2 & 0.53 \\
\hline Pimobendan ${ }^{\S}(n)$ & 9 & 4 & 5 & 0.64 \\
\hline $\operatorname{Digoxin}^{\top}(n)$ & 2 & 1 & 1 & 0.99 \\
\hline
\end{tabular}

Significantly different results are indicated with an asterisk $\left({ }^{*}\right)$; ${ }^{\dagger}$ Furosemide EG; Eurogenerics, Omega Pharma, Brussels, Belgium; ${ }^{*}$ Fortecor ${ }^{\circledR}$; Novartis Animal Health, Brussels, Belgium; 'Enacard ${ }^{\circledR}$; Merial, Anderlecht, Belgium; ${ }^{\S}$ Vetmedin ${ }^{\circledR}$; Boehringer Vetmedica GmbH, Ingelheim, Germany; ${ }^{\circledR}$ Lanoxin ${ }^{\circledR}$; GlaxoSmithKline, Genval, Belgium; DVD, degenerative valve disease; DCM, dilated cardiomyopathy; PU/PD, polyuria and polydipsia; VHS, vertebral heart size; ALT, alanine aminotransferase; NT-proANP, aminoterminal atrial natriuretic propeptide; ACE inhibitor, angiotensin-converting enzyme inhibitor.

\section{Power calculation}

The results of the power calculation are shown in Fig. 2. The statistical power of the study was $80 \%$ to identify a difference by $85 \%$ between the hazards in the treated and the placebo groups over a 24-month follow-up period.
To identify a survival difference of $70 \%$ between control and treatment groups with an $80 \%$ statistical power over a 24-month period, a minimum of 33 dogs per group would be needed. With a survival difference between groups of 20\%, 190 dogs per group would need to be included to show a significant difference over a 24-month period. 
Table 4. Progression of clinical, biochemical, neurohumoral markers over the 6- month study period in the two treatment groups

\begin{tabular}{|c|c|c|c|c|c|c|c|}
\hline Parameter & Group & $n$ & Baseline & $n$ & 3 months & $n$ & 6 months \\
\hline Cough & $\mathrm{S}$ & 9 & $0.7 \pm 0.7$ & 7 & $0.7 \pm 0.8$ & 6 & $0.7 \pm 0.5$ \\
\hline \multirow[t]{2}{*}{ Dyspnoea } & $\mathrm{S}$ & 9 & $0.2 \pm 0.4$ & 7 & $0.1 \pm 0.4$ & 6 & $0 \pm 0$ \\
\hline & $\mathrm{P}$ & 9 & $0.3 \pm 0.5$ & 7 & $0.3 \pm 0.5$ & 6 & $1.2 \pm 1.2$ \\
\hline Appetite $^{(\mathrm{a})}$ & $\mathrm{S}$ & 9 & $2.1 \pm 0.8$ & 7 & $2.1 \pm 0.7$ & 5 & $2.2 \pm 0.5$ \\
\hline Attitude $^{(\mathrm{a})}$ & $\mathrm{P}$ & 9 & $1.8 \pm 0.4$ & 7 & $2.0 \pm 0.6$ & 4 & $1.8 \pm 1.0$ \\
\hline \multirow[t]{2}{*}{ Mobility } & $\mathrm{S}$ & 9 & $2.2 \pm 0.7$ & 7 & $2.1 \pm 0.4$ & 6 & $2.0 \pm 0.6$ \\
\hline & $\mathrm{P}$ & 9 & $1.4 \pm 0.5$ & 7 & $1.6 \pm 0.5$ & 4 & $2.3 \pm 1.3$ \\
\hline \multirow[t]{2}{*}{ Activity } & $\mathrm{S}$ & 9 & $1.9 \pm 0.6$ & 7 & $1.6 \pm 0.5$ & 6 & $1.8 \pm 0.8$ \\
\hline & $\mathrm{P}$ & 9 & $1.1 \pm 0.3$ & 7 & $1.1 \pm 0.4$ & 4 & $1.5 \pm 1.0$ \\
\hline Overall score $^{(\mathrm{a})}$ & $\mathrm{S}$ & 9 & $7.1 \pm 1.8$ & 7 & $7.0 \pm 1.2$ & 6 & $6.5 \pm 2.4$ \\
\hline \multirow[t]{2}{*}{ Vomiting/diarrhoea } & $\mathrm{S}$ & 9 & 1 & 7 & 1 & 6 & 0 \\
\hline & $\mathrm{P}$ & 9 & 3 & 7 & 2 & 6 & 1 \\
\hline \multirow[t]{2}{*}{$\mathrm{PU} / \mathrm{PD}$} & $\mathrm{S}$ & 9 & 6 & 7 & 6 & 6 & 6 \\
\hline & $\mathrm{P}$ & 9 & 7 & 7 & 6 & 6 & 5 \\
\hline \multirow[t]{2}{*}{ Increased respiratory effort } & $\mathrm{S}$ & 9 & $0.2 \pm 0.4$ & 7 & $0.1 \pm 0.6$ & 6 & $0.0 \pm 0.0$ \\
\hline & $\mathrm{P}$ & 9 & $0.3 \pm 0.5$ & 7 & $0.3 \pm 0.5$ & 6 & $1.2 \pm 1.2$ \\
\hline \multirow[t]{2}{*}{ Respiratory rate } & $\mathrm{S}$ & 9 & $24.6 \pm 20.4$ & 7 & $18.4 \pm 18.2$ & 6 & $6.2 \pm 12.7$ \\
\hline & $\mathrm{P}$ & 9 & $36.3 \pm 28.5$ & 6 & $22.8 \pm 26.7$ & 5 & $51.0 \pm 40.3$ \\
\hline \multirow[t]{2}{*}{ Heart rate } & $\mathrm{S}$ & 9 & $140 \pm 30.7$ & 7 & $116 \pm 24.5$ & 6 & $119 \pm 11.7$ \\
\hline & $\mathrm{P}$ & 9 & $127 \pm 238$ & 7 & $122 \pm 24.8$ & 6 & $130 \pm 301$ \\
\hline \multirow[t]{2}{*}{ Electrocardiogram heart rate ${ }^{(a)}$} & $\mathrm{S}$ & 7 & $134 \pm 22.2$ & 6 & $128 \pm 26.4$ & 5 & $120 \pm 7.1$ \\
\hline & $\mathrm{P}$ & 9 & $146 \pm 27.4$ & 7 & $143.4 \pm 38.9$ & 5 & $131 \pm 26.0$ \\
\hline Heart failure stage $\mathrm{e}^{(\mathrm{a}),(\mathrm{b})}$ & & & & & & & \\
\hline VHS & $\mathrm{S}$ & 8 & $11.3 \pm 0.8$ & 6 & $12.0 \pm 0.8$ & 5 & $11.6 \pm 0.8$ \\
\hline & $\mathrm{P}$ & 8 & $12.3 \pm 1.3$ & 6 & $12.2 \pm 0.9$ & 6 & $12.3 \pm 1.4$ \\
\hline Plasma biochemistry & & & & & & & \\
\hline Urea $(\mathrm{mg} / \mathrm{dL})$ & $\mathrm{S}$ & 9 & $22.9 \pm 5.8$ & 7 & $24.9 \pm 7.8$ & 5 & $29.6 \pm 14.1$ \\
\hline & $\mathrm{P}$ & 8 & $26.5 \pm 14.7$ & 6 & $30.0 \pm 5.2$ & 3 & $30.0 \pm 17.7$ \\
\hline Creatinine (mg/dL) & $\mathrm{S}$ & 9 & $1.33 \pm 0.44$ & 7 & $1.29 \pm 0.32$ & 6 & $1.37 \pm 0.29$ \\
\hline & $\mathrm{P}$ & 8 & $1.36 \pm 0.34$ & 6 & $1.38 \pm 0.26$ & 3 & $1.03 \pm 0.49$ \\
\hline ALT (U/L) & $\mathrm{S}$ & 9 & $75.7 \pm 54.7$ & 7 & $98.3 \pm 134$ & 2 & $35.5 \pm 0.7$ \\
\hline & $\mathrm{P}$ & 8 & $112 \pm 129$ & 6 & $93.5 \pm 112$ & 2 & $34.5 \pm 20.5$ \\
\hline Sodium (mmol/l) & $\mathrm{S}$ & 9 & $147 \pm 3.7$ & 7 & $150 \pm 5.0$ & 5 & $142 \pm 3.9$ \\
\hline & $\mathrm{P}$ & 8 & $148 \pm 4.0$ & 6 & $145 \pm 4.4$ & 3 & $147 \pm 7.1$ \\
\hline Potassium (mmol/l) & $\mathrm{S}$ & 9 & $4.4 \pm 0.6$ & 7 & $4.1 \pm 0.5$ & 6 & $3.9 \pm 0.5$ \\
\hline & $\mathrm{P}$ & 8 & $3.8 \pm 0.3$ & 6 & $3.7 \pm 0.4$ & 3 & $4.2 \pm 0.5$ \\
\hline Neuroendocrine markers & & & & & & & \\
\hline NT-proANP (fmol/l) ${ }^{(\mathrm{a}),(\mathrm{b})}$ & $\mathrm{S}$ & 9 & $0.70 \pm 0.41$ & 7 & $0.83 \pm 0.55$ & 5 & $0.83 \pm 0.44$ \\
\hline & $\mathrm{P}$ & 7 & $0.95 \pm 0.51$ & 6 & $0.47 \pm 0.46$ & 2 & $0.32 \pm 0.29$ \\
\hline Aldosterone (pmol/l) & $\mathrm{S}$ & 9 & $147 \pm 144$ & 7 & $96.5 \pm 62.3$ & 2 & $104 \pm 32.2$ \\
\hline & $\mathrm{P}$ & 7 & $129 \pm 76.3$ & 5 & $172 \pm 144$ & 1 & 216 \\
\hline
\end{tabular}

Parameters with significant time evolution are indicated with (a), parameters showing significantly different evolution between the two treatment groups are indicated with (b); Heart Failure Stage according to Scandinavian modified New York Heart Association System for heart failure classification in dogs with mitral valve disease (Table 1); S, spironolactone; P, placebo; PU/PD, polyuria and polydipsia; VHS, vertebral heart size; ALT, alanine aminotransferase; NT-proANP, aminoterminal atrial natriuretic propeptide. 


\begin{tabular}{|c|c|c|c|c|c|c|c|}
\hline Parameter & Group & $n$ & Baseline & $n$ & 3 months & $n$ & 6 months \\
\hline \multirow[t]{2}{*}{ IVSd (mm) } & S & 8 & $8.7 \pm 2.9$ & 7 & $9.1 \pm 3.5$ & 5 & $11.3 \pm 3.7$ \\
\hline & $\mathrm{P}$ & 9 & $8.9 \pm 2.9$ & 7 & $8.5 \pm 4.0$ & 6 & $6.8 \pm 2.3$ \\
\hline \multirow[t]{2}{*}{ IVSs (mm) } & S & 8 & $13.8 \pm 3.5$ & 7 & $13.8 \pm 4.5$ & 5 & $14.4 \pm 5.1$ \\
\hline & $\mathrm{P}$ & 9 & $12.3 \pm 3.0$ & 7 & $12.6 \pm 3.6$ & 6 & $12.7 \pm 1.9$ \\
\hline \multirow[t]{2}{*}{ LVd (mm) } & S & 8 & $52.3 \pm 20.1$ & 7 & $49.1 \pm 19.6$ & 5 & $47.1 \pm 19.5$ \\
\hline & $\mathrm{P}$ & 9 & $49.3 \pm 17.2$ & 7 & $48.9 \pm 18.6$ & 6 & $52.5 \pm 21.0$ \\
\hline \multirow[t]{2}{*}{ LVs (mm) } & S & 8 & $35.8 \pm 17.4$ & 7 & $31.8 \pm 16.5$ & 5 & $34.1 \pm 17.1$ \\
\hline & $\mathrm{P}$ & 9 & $36.0 \pm 20.7$ & 7 & $35.8 \pm 22.2$ & 6 & $35.6 \pm 24.2$ \\
\hline \multirow[t]{2}{*}{ PWd (mm) } & S & 8 & $9.1 \pm 2.7$ & 7 & $10.7 \pm 5.2$ & 5 & $10.2 \pm 3.1$ \\
\hline & $\mathrm{P}$ & 9 & $8.1 \pm 2.0$ & 7 & $8.4 \pm 2.6$ & 6 & $7.6 \pm 1.9$ \\
\hline \multirow[t]{2}{*}{ PWs (mm) } & S & 8 & $13.4 \pm 3.6$ & 7 & $14.8 \pm 4.8$ & 5 & $14.9 \pm 4.2$ \\
\hline & $\mathrm{P}$ & 9 & $10.6 \pm 2.1$ & 7 & $9.3 \pm 5.1$ & 6 & $12.3 \pm 2.9$ \\
\hline \multirow[t]{2}{*}{ FS (\%) } & S & 8 & $37.1 \pm 12.9$ & 7 & $37.9 \pm 11.9$ & 5 & $29.0 \pm 13.4$ \\
\hline & $\mathrm{P}$ & 9 & $31.3 \pm 16.2$ & 7 & $31.7 \pm 19.6$ & 6 & $34.0 \pm 15.9$ \\
\hline \multirow[t]{2}{*}{ EPSS (mm) } & S & 8 & $6.7 \pm 6.4$ & 7 & $6.2 \pm 6.0$ & 4 & $3.6 \pm 2.7$ \\
\hline & $\mathrm{P}$ & 8 & $6.7 \pm 7.3$ & 7 & $2.1 \pm 1.6$ & 4 & $5.9 \pm 8.1$ \\
\hline \multirow[t]{2}{*}{ LA2D (mm) } & S & 7 & $40.9 \pm 24.9$ & 6 & $48.4 \pm 23.6$ & 5 & $41.6 \pm 24.1$ \\
\hline & $\mathrm{P}$ & 9 & $43.8 \pm 10.3$ & 5 & $50.3 \pm 3.8$ & 3 & $49.5 \pm 11.7$ \\
\hline \multirow[t]{2}{*}{ Ao/LA } & S & 7 & $1.65 \pm 0.84$ & 6 & $2.00 \pm 0.83$ & 5 & $2.19 \pm 0.50$ \\
\hline & $\mathrm{P}$ & 6 & $2.37 \pm 0.90$ & 5 & $2.51 \pm 0.47$ & 2 & $1.70 \pm 1.13$ \\
\hline \multirow[t]{2}{*}{ Ao $(\mathrm{m} / \mathrm{s})^{(\mathrm{a})}$} & S & 6 & $0.81 \pm 0.37$ & 6 & $1.09 \pm 0.31$ & 5 & $1.04 \pm 0.43$ \\
\hline & $\mathrm{P}$ & 9 & $1.34 \pm 0.62$ & 6 & $1.04 \pm 0.21$ & 4 & $1.19 \pm 0.10$ \\
\hline \multirow[t]{2}{*}{$\mathrm{PA}(\mathrm{m} / \mathrm{s})$} & S & 8 & $0.66 \pm 0.09$ & 7 & $0.68 \pm 0.22$ & 5 & $0.67 \pm 0.17$ \\
\hline & $\mathrm{P}$ & 8 & $0.68 \pm 0.18$ & 7 & $0.69 \pm 0.28$ & 2 & $0.94 \pm 0.12$ \\
\hline \multirow[t]{2}{*}{ PEP (ms) } & S & 6 & $65.5 \pm 17.9$ & 6 & $55.8 \pm 25.5$ & 5 & $55.7 \pm 17.9$ \\
\hline & $\mathrm{P}$ & 8 & $68.9 \pm 23.9$ & 5 & $58.2 \pm 12.5$ & 3 & $60.7 \pm 31.0$ \\
\hline \multirow[t]{2}{*}{ ET (ms) } & $\mathrm{S}$ & 6 & $155 \pm 17.4$ & 6 & $156 \pm 26.8$ & 5 & $156 \pm 29.6$ \\
\hline & $\mathrm{P}$ & 8 & $162 \pm 29.8$ & 5 & $149 \pm 32.3$ & 3 & $148 \pm 32.9$ \\
\hline \multirow[t]{2}{*}{$\mathrm{PEP} / \mathrm{ET}$} & $S$ & 6 & $0.43 \pm 0.14$ & 6 & $0.38 \pm 0.21$ & 5 & $0.37 \pm 0.12$ \\
\hline & $\mathrm{P}$ & 8 & $0.44 \pm 0.18$ & 5 & $0.41 \pm 0.14$ & 3 & $0.39 \pm 0.18$ \\
\hline \multirow[t]{2}{*}{$\mathrm{MV} \mathrm{E} / \mathrm{A}$} & $S$ & 4 & $2.45 \pm 1.17$ & 3 & $2.33 \pm 0.67$ & 3 & $1.30 \pm 0.26$ \\
\hline & $\mathrm{P}$ & 6 & $2.28 \pm 1.35$ & 6 & $1.72 \pm 0.54$ & 3 & $1.68 \pm 0.57$ \\
\hline \multirow[t]{2}{*}{ EVedt $(\mathrm{m} / \mathrm{s})$} & $S$ & 5 & $45.3 \pm 20.6$ & 3 & $36.2 \pm 5.5$ & 3 & $31.0 \pm 7.2$ \\
\hline & $\mathrm{P}$ & 6 & $47.9 \pm 34.0$ & 5 & $40.4 \pm 17.8$ & 0 & - \\
\hline
\end{tabular}

Table 5. Haemodynamic parameters over the 6- month study period in the two treatment groups

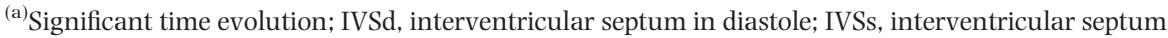
in systole; LVd, left ventricular diameter in diastole; LVs, left ventricular diameter in systole; PWd, posterior wall in diastole; PWs, posterior wall in systole; FS, fractional shortening; EPSS, mitral E-point septal separation; LA 2D, left atrial size before the opening of the mitral valve in the right parasternal long-axis view; Ao/LA, internal aortic diameter (Ao) and left atrial diameter from the right parasternal short-axis view; Ao, maximal aortic outflow velocity; PA, maximal pulmonic outflow velocity; PEP, pre-ejection period; ET, ejection time; MV E/A, mitral inflow E/A ratio; MV Edt, mitral inflow deceleration time of the E-wave.
}

\section{DISCUSSION}

The aim of this randomized prospective double-blinded placebocontrolled clinical study was to assess the efficacy and tolerance of spironolactone when added at a low dose to conventional heart failure treatment in dogs with advanced heart failure due to either DVD or DCM.

The results of this study show that addition of spironolactone at a dose between 0.49 and $0.8 \mathrm{mg} / \mathrm{kg}$ per day to conventional heart failure treatment was not associated with any adverse events. In particular, there was no measurable effect on plasma potassium concentrations. This finding is of importance, given reports of life-threatening hyperkalaemia in human patients treated with a combination of ACE inhibitors and spironolactone (Berry \& McMurray, 2001; Juurlink et al., 2004). The present results are in accordance with the findings of Thomason et al. (2007) and Bernay et al. (2010), who reported no significant difference in serum potassium in dogs with DVD treated with a combination of ACE inhibitors and spironolactone at a mean dose of $1.49 \pm 0.54 \mathrm{mg} / \mathrm{kg}$ twice daily and $2.33 \pm 0.34 \mathrm{mg} / \mathrm{kg}$ once daily, respectively.

In this present study, no significant effect of spironolactone on survival could be shown. Dogs in the control group had a higher risk of moving into a higher heart failure stage than dogs in the spironolactone group during the 6 months of the trial. This might indicate a potential beneficial effect of spironolactone on the progression of heart failure, but this finding was not supported by other parameters evaluated in this study such as clinical score, ECG abnormalities, blood pressure, VHS and haemodynamic parameters. 


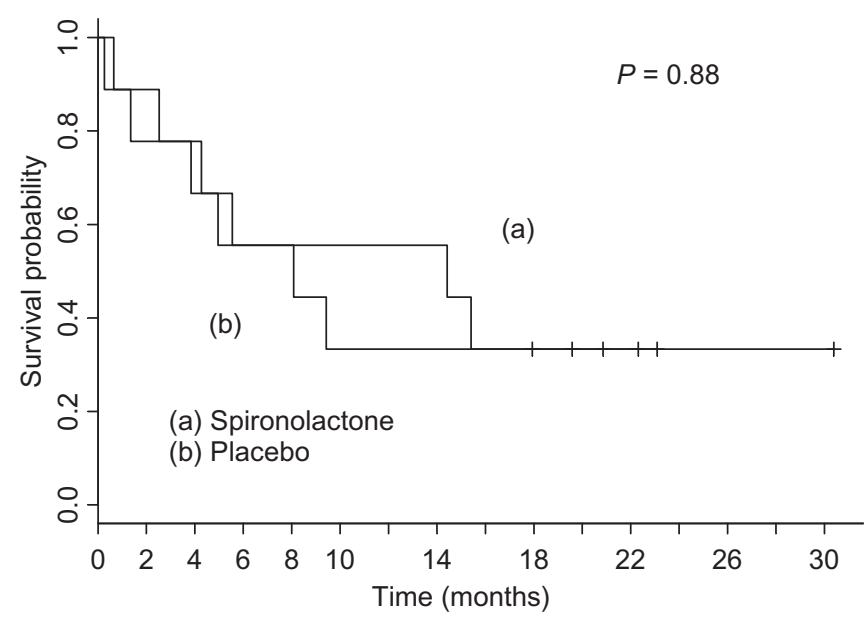

Fig. 1. Kaplan-Meier Curve showing lack of survival benefit in dogs with advanced degenerative valve disease or dilated cardiomyopathy treated with low-dose spironolactone in addition to conventional congestive heart failure treatment.

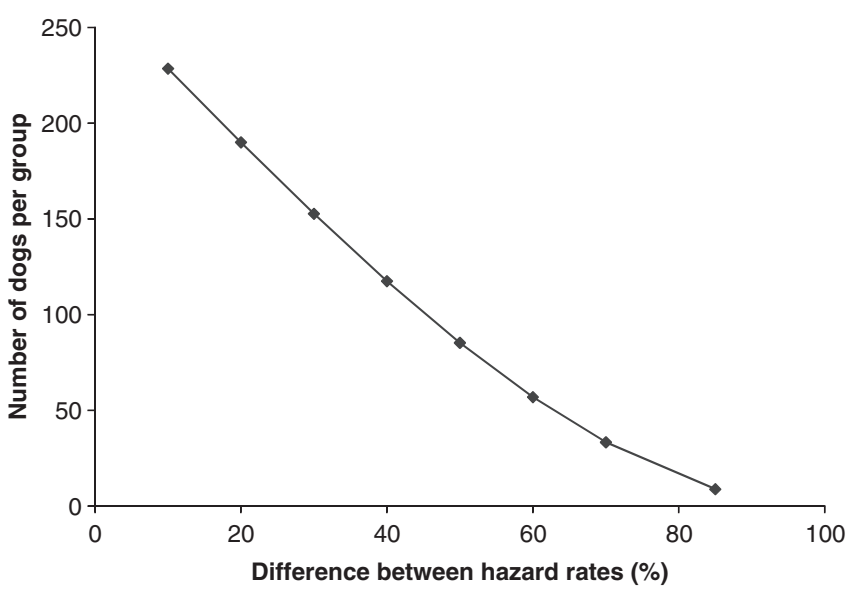

Fig. 2. Power calculation showing the minimum number of dogs per group needed to show a difference with an $80 \%$ statistical power over a 24- month period between the treatment and control groups. The hazard rate is the number of instantaneous deaths. According to the calculation, a minimum of 33 dogs per group are needed to show a significant difference between groups with a survival difference between groups of $70 \%$.

The findings of the present study differ from human data from the RALES (Pitt et al., 1999) and the study performed by Bernay et al. (2010) in a population of dogs with moderate to severe mitral valve disease. In the latter study, which was a prospective, placebo-controlled field trial including 212 dogs, a $69 \%$ reduction in risk of cardiac death or euthanasia was reported for the spironolactone group.

The exact mechanism of the potential beneficial effects of spironolactone in patients with heart failure is uncertain and may be multifactorial. There is strong evidence from humans and various animal heart failure models that mineralocorticoid receptor antagonists, such as spironolactone, reduce excessive extracellular matrix turnover and myocardial remodelling, thus slowing down progression of heart disease (Rousseau et al., 2002; Suzuki et al., 2002; Hayashi et al., 2003; Karram et al., 2005). Study of a subgroup of the RALES patient population showed a significant decrease in BNP and NT-proANP associated with an increase in angiotensin II and aldosterone in patients treated with low-dose spironolactone, indicating effective aldosterone receptor blockade (Rousseau et al., 2002). These findings provide further evidence for a potential neuroendocrine modulation as mechanism of action for the beneficial effects of spironolactone in heart failure patients (Rousseau et al., 2002).

The lack of a measurable beneficial effect of spironolactone in this population of dogs could be a result of several factors including a small patient population, insufficient treatment dose and differences in baseline characteristics between spironolactone and control group.

The small patient number is a major limitation of this study. Power calculation performed after completion of the study showed that the number of dogs included was insufficient to conclusively demonstrate or disprove a survival benefit. Based on this data, up to 200 dogs per treatment group may be required to be able to show a significant difference between treatment groups. Such large patient numbers can only be completed in reasonable time using a multicentre approach, which have their own limitations, such as increased interobserver variability.

The low dose of spironolactone used may be another possible explanation for the lack of a detectable clinical effect of spironolactone in this study. This study was modelled after the RALES trial in which a low dose of $25 \mathrm{mg}$ /person was used in an effort to avoid diuresis (Pitt et al., 1999). We aimed at using a dose, which would be clearly below the approved diuretic dose in dogs (2-4 mg/kg once daily), to be able to show that potential positive effects of spironolactone are in fact due to other than diuretic effects. Specific pharmacological data from dogs were not available at the time of the study, thus the dose of 0.49 $0.8 \mathrm{mg} / \mathrm{kg}$ once daily was chosen. In the meantime, data from a canine hyperaldosterone model, which was specifically designed to determine an effective dose of spironolactone for the management of congestive heart failure in dogs, has been published. In this experimental model a spironolactone dose of $1.08 \pm 0.28 \mathrm{mg} / \mathrm{kg}$ only inhibited aldosterone actions by $50 \%$. (Guyonnet et al., 2009). Based on these results, it is likely that the dose used in the present trial was too low to provide sufficient aldosterone receptor blockade. This hypothesis is supported by the fact that plasma aldosterone did not increase in dogs in the spironolactone group during treatment which is in contrast to humans in the RALES study in which plasma aldosterone concentrations increased during treatment indicating activated feedback mechanisms (Rousseau et al., 2002). A lack of effective aldosterone receptor blockage could explain the differences in outcome between the present study and the study of Bernay et al. (2010), in which a mean daily dose of spironolactone of $2.33 \pm 0.34 \mathrm{mg} / \mathrm{kg}$ was used. Based on these findings, the use of a dose of $2 \mathrm{mg} / \mathrm{kg}$ once daily is advocated for further trials and active metabolites of spironolactone as well as plasma aldosterone should be measured to ascertain effective aldosterone 
receptor blockade as well as owner compliance. These findings also emphasize the importance of dose-finding trials ahead of the study of specific clinical outcomes in relation to drug therapy.

There were some differences between the two treatment groups at baseline, which could account for the lack of measurable beneficial effect of spironolactone. Three dogs in the spironolactone group but only one dog in the control group showed atrial fibrillation, which may suggest more advanced disease and a potentially poorer prognosis in the dogs in this group (Calvert et al., 1997). Secondly, there was a higher overall clinical score in the spironolactone group at baseline. When this difference was detected, the clinical score was introduced as a covariant into the statistical model to exclude bias because of existing baseline differences. However, even after adjustment for the difference in the baseline clinical scores, no significant effect of spironolactone could be found. On the other hand, dogs with DCM and DVD were equally distributed between the two treatment groups and the mean daily dose of furosemide, which can be used as an indicator of severity of cardiac disease, was not significantly different between treatment groups (Smith et al., 2005).

Other findings of this study were, firstly, that dogs with DVD were significantly more likely to be presenting cough, which could be secondary to a relatively larger left atrial size because of more marked mitral regurgitation, leading to compression of the left mainstem bronchus. Secondly, it was found that the total daily dose of furosemide was inversely correlated with survival, which underlines the value of this parameter as a marker of severity of heart failure (Smith et al., 2005). The results of this study showed no effect of pimobendan on survival; however, this was not an endpoint of the study.

Plasma aldosterone and NT-proANP were assessed as neuroendocrine markers of heart failure. The results have to be interpreted with caution given that only a limited number of samples could be assessed, especially at 6 months. Plasma aldosterone was unaffected by spironolactone treatment. NTproANP increased significantly over time in the spironolactone group and significantly decreased in the control group. This finding was unexpected. Human patients with hyperaldosteronism typically show high plasma ANP concentrations, which acts to counterbalance the aldosterone-induced sodium and water retention (Levin et al., 1998). Therefore, with aldosterone receptor blockade via spironolactone, a decrease rather than an increase in NT-proANP had been expected. However, increases in NT-proANP may explain the lack of a survival benefit in the spironolactone group. NT-proANP has been associated with substantially decreased survival times in humans with congestive heart failure (Dickstein et al., 1998). It was highly correlated with heart rate, echocardiographic dimensions of the left atrium and left ventricle and fractional shortening in dogs with DCM as well as enlargement of the left atrium and ventricle in dogs with chronic valvular disease and could therefore indicate that dogs in the spironolactone group had potentially more advanced heart disease (Häggström et al., 1994; Tidholm et al., 2001).
This study is of relevance for future trials. Firstly, the study design proved to be feasible in the setting of a busy teaching hospital. Secondly, power calculation indicated that at least 66 patients need to be included in the study to be able to show significant survival differences between treatment groups assuming a reduction in survival of $69 \%$, as described by Bernay et al., 2010. Therefore, a multicentre approach should be applied. Thirdly, a higher dose of spironolactone should be used, and active metabolites in plasma should be monitored to prove that an effective dose is used and to verify owner compliance.

\section{CONCLUSIONS}

In conclusion, it can be stated that addition of spironolactone at a low dose to conventional heart failure treatment (furosemide, ACE inhibitor, pimobendan, digoxin) in dogs with acquired heart disease is well tolerated. It may improve heart failure class but beneficial effects on survival could not be shown in this study.

\section{ACKNOWLEDGMENTS}

This study was supported by a grant of the Fonds National de la Recherche Scientifique (FRNS) of the University of Liège, Belgium and by CEVA santé animale. The authors acknowledge Novartis Animal Health for providing free treatment with benazepril $\left(\right.$ Fortekor ${ }^{\circledR}$ ) for the participating dogs during the period of the trial as well as all technical and academic staff and students of the University of Liège, who helped with the clinical management of the cases. Pascale Jespers and Suzanne Foulon, technicians at the University of Brussels, are acknowledged in particular for performing the radio-immunoassays for assessment of the neuro-endocrine parameters. The authors also thank Prof. Hervé Lefebvre (DVM, PhD, DECVPT) and Prof. Didier Concordet from the Ecole Nationale Vétérinaire de Toulouse (France) for their invaluable advice and for performing the power analysis.

The results of this study were presented at the 16th Annual Conference of the European College of Veterinary Internal Medicine - Companion Animals (ECVIM-CA), 14-16th September 2006, Amsterdam, the Netherlands.

\section{REFERENCES}

BENCH study (1999) The effect of benazepril on survival times and clinical signs of dogs with congestive heart failure: results of multicenter prospective, randomized, double blinded, placebo controlled, long term, clinical trial. Journal of Veterinary Cardiology, 1, 7-18.

Bernay, F., Bland, J.M., Häggström, J., Baduel, L., Combes, B., Lopez, A. \& Klaltsatos, V. (2010) Efficacy of spironolactone on survival in dogs with naturally occurring mitral regurgitation caused by myxomatous mitral valve disease. Journal of Veterinary Internal Medicine, 24, 331-341. 
Berry, C. \& McMurray, J.J. (2001) Serious adverse events experience by patients with chronic heart failure taking spironolactone. Heart, 85, E8.

Buchanan, J.W. \& Bücheler, J. (1995) Vertebral scale system to measure canine heart size in radiographs. Journal of the American Veterinary Medical Association, 206, 459-489.

Calvert, C.A., Pickus, C.W., Jacobs, G.J. \& Brown, J. (1997) Signalment, survival, and prognostic factors in Doberman pinschers with endstage cardiomyopathy. Journal of Veterinary Internal Medicine, 11, 323-326.

CONSENSUS study group (1987) Effects of enalapril on mortality in severe congestive heart failure. Results of the cooperative north Scandinavian Enalapril Study group. New England Journal of Medicine, 316, 1429-1435.

COVE study (1995) Controlled clinical evaluation of enalapril in dogs with heart failure: results of the Cooperative Veterinary Enalapril Study group. Journal of Veterinary Internal Medicine, 9, 243-252.

Dickstein, K., Abrahamsen, S. \& Aarsland, T. (1998) Plasma N-terminal atrial natriuretic peptide predicts hospitalization in patients with heart failure. Scandinavian Cardiovascular Journal, 32, 361-364.

Ettinger, S.J., Benitz, A.M., Ericsson, G.F., Cifelli, S., Jernigan, A.D., Longhofer, S.L., Trimboli, W. \& Hanson, P.D. (1998) Effects of enalapril maleate on survival of dogs with naturally acquired heart failure. The long-term investigation of Veterinary Enalapril (LIVE) study group. Journal of the American Veterinary Medical Association, 213, 1573-1577.

Guyonnet, J., Elliott, J. \& Kaltsatos, V. (2009) A preclinical pharmacokinetic and pharmacodynamic approach to determine a dose of spironolactone for treatment of congestive heart failure in dogs. Journal of Veterinary Pharmacology and Therapeutics, 33, 260-267.

Häggström, J., Hansson, K., Karlberg, B.E., Kvart, C. \& Olsson, K. (1994) Plasma concentration of atrial natriuretic peptide in relation to severity of mitral regurgitation in Cavalier King Charles Spaniels. American Journal of Veterinary Research, 55, 698-703.

Hayashi, M., Tsutamoto, T., Wada, A., Tsutsui, T., Ishii, C., Ohno, K., Fujii, M., Taniguchi, A., Hamatani, T., Nozato, Y., Kataoka, K., Morigami, N., Ohnishi, M., Kinoshita, M. \& Horie, M. (2003) Immediate administration of mineralocorticoid receptor antagonist spironolactone prevents post-infarct left ventricular remodeling associated with suppression of a marker of myocardial collagen synthesis in patients with first anterior acute myocardial infarction. Circulation, 107, 2559-2565.

IMPROVE study (1995) Acute and short-term haemodynamic, echocardiographic and clinical effects of enalapril maleate in dogs with naturally acquired heart failure: results of invasive multicenter prospective veterinary evaluation of enalapril. Journal of Veterinary Internal Medicine, 9, 234-242.

Juurlink, D.N., Mamdani, M.M., Lee, D.S., Kopp, A., Austin, P.C., Laupacis, A. \& Redelmeier, D.A. (2004) Rates of hyperkalemia after publication of the randomized aldactone evaluation study. New England Journal of Medicine, 351, 543-551.

Karram, T., Abbasi, A., Keidar, S., Golomb, E., Hochberg, I., Winaver, J., Hoffman, A. \& Abassi, Z. (2005) Effects of spironolactone and eprosartan on cardiac remodeling and angiotensin-converting enzyme isoforms in rats with experimental heart failure. American Journal of Physiology - Heart and Circulatory Physiology, 289, H1351-H1358.

Katz, A.M. (2003) Heart failure: a hemodynamic disorder complicated by maladaptive proliferative responses. Journal of Cellular and Molecular Medicine, 7, 1-10.

Lachin, J.M. \& Foulkes, M.A. (1986) Evaluation of sample size and power for analyses of survival with allowance for nonuniform patient entry, losses of follow up, noncompliance, and stratification. Biometrics, 42, 507-519.
Levin, E.R., Gardner, D.G. \& Samson, W.K. (1998) Natriuretic peptides. New England Journal of Medicine, 339, 321-328.

MacFadyen, R.J., Lee, A.F., Morton, J.J., Pringle, S.D. \& Struthers, A.D. (1999) How often are angiotensin II and aldosterone concentrations raised during chronic ACE inhibitor treatment in cardiac failure? Heart, 82, 57-61.

O'Grady, M.R., Bonagura, J.D., Powers, J.D. \& Herring, D.S. (2005) Quantitative cross-sectional echocardiography in the normal dog. Veterinary Radiology, 27, 34-49.

Pitt, B., Zannad, F., Remme, W.J., Cody, R., Castaigne, A., Perez, A., Palensky, J. \& Wittes, J. (1999) The effect of Spironolactone on morbidity and mortality in patients with severe heart failure. New England Journal of Medicine, 341, 709-717.

Rousseau, M.F., Gurné, O., Duprez, D., Van Mieghem, W., Robert, A., Ahn, S., Galanti, L. \& Ketelslegers, J.M. (2002) Belgian RALES Investigators. Beneficial neurohormonal profile of spironolactone in severe congestive heart failure: results from the RALES neurohormonal substudy. Journal of the American College of Cardiology, 40, 1596-1601.

Schiller, N.B., Shah, P.M., Crawford, M., DeMaria, A., Devereux, R., Feigenbaum, H., Gutgesell, H., Reichek, N., Sahn, D. \& Schnittger, I. (1989) Recommendations for quantitation of the left ventricle by two-dimensional echocardiography. American Society of Echocardiography Committee on Standards, Subcommittee on Quantitation of Two-Dimensional Echocardiograms. Journal of the American Society for Echocardiography, 2, 358-367.

Smith, P.J., French, A.T., Van Israël, N., Smith, S.G., Swift, S.T., Lee, A.J., Corcoran, B.M. \& Dukes-McEwan, J. (2005) Efficacy and safety of pimobendan in canine heart failure caused by myxomatous mitral valve disease. Journal of Small Animal Practice, 46, 121-130.

Struthers, A.D. (2004) The clinical implications of aldosterone escape in congestive heart failure. European Journal of Heart Failure, 6, 539-545.

Suzuki, G., Morita, H., Mishima, T., Sharov, V.G., Todor, A., Tanhehco, E.J., Rudolph, A.E., McMahon, E.G., Goldstein, S. \& Sabbah, H.N. (2002) Effects of long-term monotherapy with eplerenone, a novel aldosterone blocker, on progression of left ventricular dysfunction and remodeling in dogs with heart failure. Circulation, 106, 2967-2972.

Swedberg, K., Eneroth, P., Kjekshus, J. \& Wilhelmsen, L. (1990) Hormones regulating cardiovascular function in patients with severe congestive heart failure and their relation to mortality. Circulation, 82, 1730-1736.

Thomason, J.D., Rockwell, J.E., Fallaw, T.K. \& Calvert, C.A. (2007) Influence of combined angiotensin-converting enzyme inhibitors and spironolactone on serum $\mathrm{K}+, \mathrm{Mg} 2+$, and $\mathrm{Na}+$ concentrations in small dogs with degenerative mitral valve disease. Journal of Veterinary Cardiology, 11, 103-108.

Tidholm, A., Häggström, J. \& Hansson, K. (2001) Effects of dilated cardiomyopathy on the renin-angiotensin-aldosterone system, atrial natriuretic peptide activity, and thyroid hormone concentrations in dogs. American Journal of Veterinary Research, 62, 961-967.

Van de Wal, R.M., Plokker, H.W., Lok, D.J., Boomsma, F., van der Horst, F.A., van Veldhuisen, D.J., van Gilst, W.H. \& Voors, A.A. (2006) Determinants of increased angiotensin II levels in severe chronic heart failure patients despite ACE inhibition. International Journal of Cardiology, 106, 367-372.

Zannad, F., Alla, F., Dousset, B., Perez, A. \& Pitt, B. (2000) Limitation of excessive extracellular matrix turnover may contribute to survival benefit of therapy in patients with congestive heart failure: insights from the randomized aldactone evaluation study (RALES). Rales Investigators. Circulation, 102, 2700-2706. 